\title{
Intraventricular tuberculoma: A case report ${ }^{*}$
}

\author{
O. Coulibaly\#, S. Diawara, K. Quénum, Y. Sogoba, M. Boutarbouch, A. Melhaoui, L. Rifi, \\ Y. Arkha, S. Derraz, A. El Ouahabi, A. El Khamlichi
}

Department of Neurosurgery, CHU IbnSina, Rabat, Morocco; ${ }^{\#}$ Corresponding Author: coulibalynch1@gmail.com

Received 24 January 2013; revised 27 February 2013; accepted 14 March 2013

\begin{abstract}
Intracranial tuberculomas are one of the most serious formsof tuberculosis disease after meningitis tuberculosis. It incidence varies around $0.15 \%-0.18 \%$ in the development world to $5 \%$ $30 \%$ of intracranial masses in some under developments areas. These tuberculomas, of course ubiquitous, are mostly diagnosed in the adulthood and usually located in the cerebellum and the cerebral hemispheres. Intra ventricular involving is uncommon and just 10 cases had been described in the literature. We report a case of an intraventricular tuberculoma in a 26year-old man and we discuss the pathogenesis and the radiological findings according this location.
\end{abstract}

Keywords: Intracranial Tuberculosis; Intraventricular Tuberculoma; Antituberculous Treatment

\section{INTRODUCTION}

An intracranial tuberculoma results from hematogenous spreading of tubercle bacilli to the leptomeninges or brainparenchyma [1]. Thesecentral nervous system (CNS) spreading of tuberculosis disease occur by two main interrelated pathological processes, in the form of tuberculosis (TB) meningitis or intracranial tuberculomas. The incidence of this one varies around $0.15 \%-0.18 \%$ in the development world to $5 \%$ - 30\% of intracranial masses in some under developments areas [2-4]. According to the World Health Organization, there are approximately 8.7 million new TB cases and 990,000 deaths every year. This incidence increases slightly in HIV people (1.1 million) with $7 \%$ of mortality in this people [5]. The increasing of this disease worldwide should be taken seriously especially in countries in which AIDS (Acquired Immunodeficiency Syndrom) continues to be a pandemic disease. So, intracranial tuberculomaalone remainstoo a

*The authors have no personal financial or institutional interest in any of the drugs, materials, or devices described in this article. serious, often fatal disease in some areas and affects predominantly young people.

These intracranial tuberculomascan mimic other intracranial space-occupying lesions and must be diagnosed early and managed promptly in order to prevent this mortality or to reduce thiscomorbidity.

Despite recent advances in imaging (MRI with spectroscopy) and laboratoriestechniques, the diagnosis of intracranial tuberculoma remains a challenge, but can be strongly suspected and should be confirmed histologically.

In this paper, we described here a case of an intraventricular tuberculoma in a 26-year-old man and we discussed the pathogenesis and the radiological findings according this exceptional location.

\section{CASE REPORT}

A 26-year-old man, with no medical history was admitted within our department for 04 months history of headaches, vomiting and loss of visual acuity. In our interrogatory, this patient had not been treated before for anything, especially tuberculosis. Neurological examination found a fully conscientious patient with stiff neck in bad general condition, bilateral loss of visual acuity $(4 / 10)$ withbilateral papilledema. There is no fever and any evident of neurological deficit.

Computer tomography (CT) scanshowed around hypodense intraventricular lesionin the light of the fourth ventricle with major edema, heterogeneous enhancement after contrast injection and hydrocephalus. Resonance magnetic imaging was performed to well definite, locate this lesion and assess the modality of surgical procedure. Magnetic resonance imaging (MRI) T1 weighted images showed a well-defined round hypointense lesion enclosed in the right occipital horn withhuge peripheral edema and asymmetric hydrocephalus, with homogeneous and en cocarde enhancement after gadolinium injection. On T2 weighted images, this lesion was spontaneous hypointense with peripheral edema (Figure 1).

In the doubt, he underwent a parietooccipital procedure that permitted to obtain the wholly gross total resection of this tumor after puncture of the right occipital 


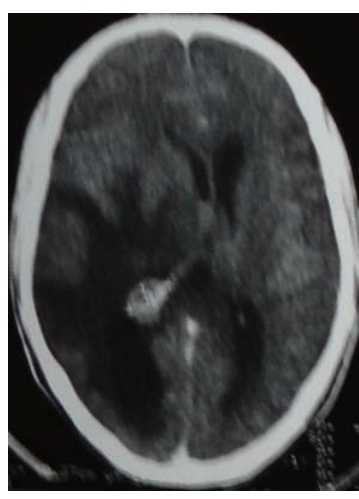

(a)

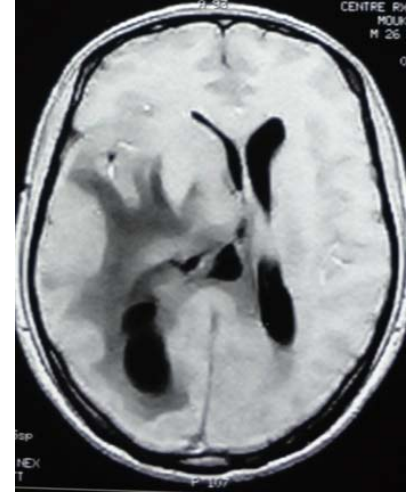

(b)

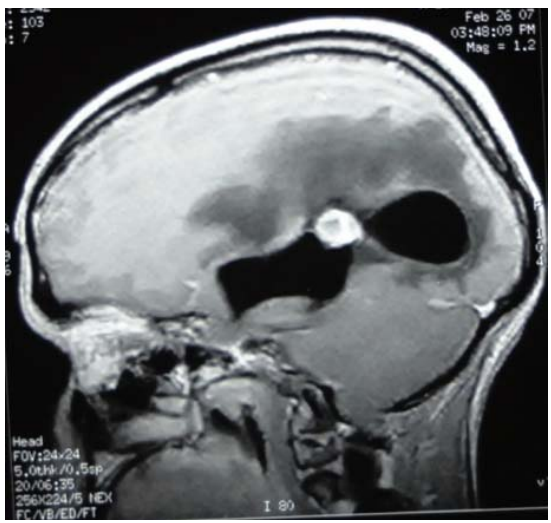

(e)

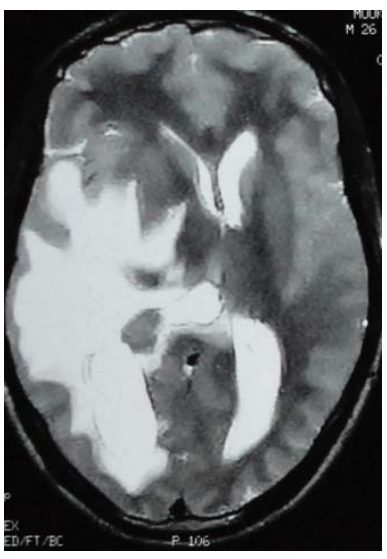

(c)

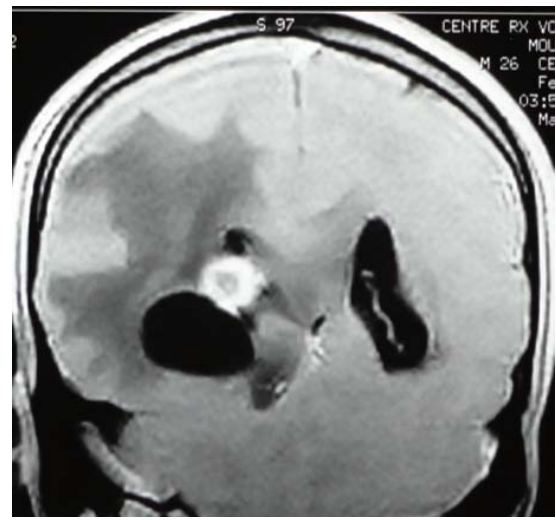

(f)

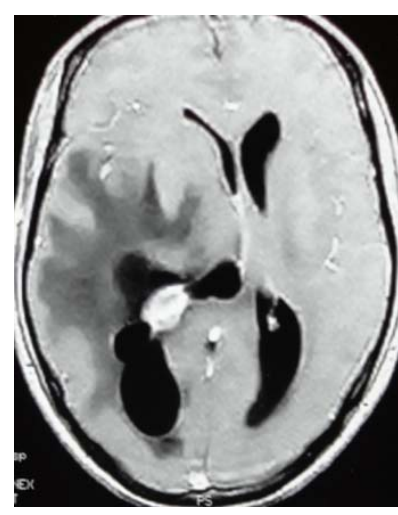

(d)

Figure 1. 1) CT scan with contrast injection showing an intraventricular mass with disproportinnal hydrocephalus and huge peripheral edema (a). 2) MRI Axial non contrast T1-weighted image shows a hypointense lesion within the right occipital horn with asymetric hydrocephalus and huge peripheral edema (b). Axial T2-weighted image shows this huge edema centred on this hypointense intraventricular lesion (c). Contrast enhanced images on axial (d), sagital (e) and coronal (f) view shows the characterictic ring enhancement of the lesion with a central hypointense area.

horn by the trocar of Cushing following by the establishment of an external ventricular drainage. Per operatively, it was seen an avascular yellow creamy tumor adherent to the plexus choroid compatible to the diagnosis of intraventriculartuberculoma. Cerebrospinal fluid examinations showed a citrine liquid composed of 60 cells/ $\mathrm{mm}^{3}$ with $88 \%$ lymphocytes, hypoglycorrhachia $(0.28 \mathrm{~g} / \mathrm{l})$ with high level of protein. Histopathological examination revealed that this lesion was composed of epithelioid histiocytes, langhans-type giant cells, and lymphocytes with wide range of caseating necrosis confirming the diagnosis of tuberculoma. The external ventricular drainage was removed on the 6th day. The patient was discharged from hospital ten days after surgery on corticoids (Solumedrol $2 \mathrm{mg} / \mathrm{kg}$ per day) for three months, on antituberculous treatment basing on two months of streptomycin (0.75 $\mathrm{mg}$ per day), isoniazid ( $5 \mathrm{mg} / \mathrm{kg}$ per day), rifampicin (10 $\mathrm{mg} / \mathrm{kg}$ per day) and pyrazinamide ( $25 \mathrm{mg} / \mathrm{kg}$ per day) following by 10 months of rifampicin and isoniazid. CT scan at 3 and 12 months showed a total disappearance of the lesion, leaving behind a hypodense lesion as a sequella (Figure 2).

\section{DISCUSSION}

Intraventricular tuberculoma is a nosological entity rarely described in the literature, only 10 cases had been published before our case. Certainly exceptional, ventricular involvement in the tuberculous process (future tuberculoma) come probably from hematogenous spread that occurs as choroid plexus inflammation characterized by a covering of gelatinous exudates, ependymitis and asymmetric hydrocephalus secondary to intraventricular adhesions or septae formation [2,6-8]. Tubercles (Rich foci) have been found within the choroid plexus, but well-developed intraventricular tuberculoma are extremely rare, probably due to the special immunity of the ventricles to infections [9].

The characteristic CT features of intraventriculartuberculoma are peripheral enhancement with central necrosis and disproportionately extensive cerebral edema 


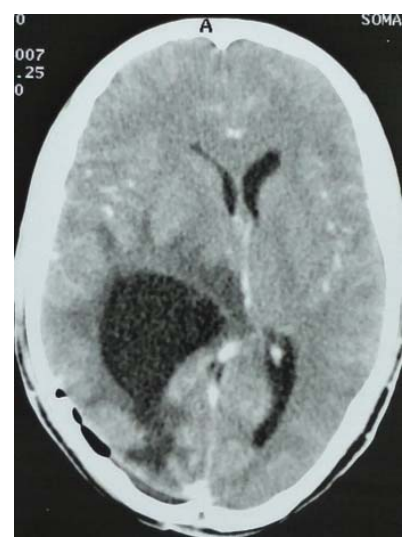

(a)

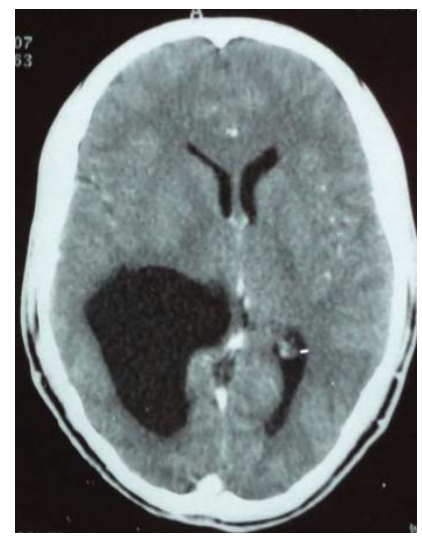

(b)

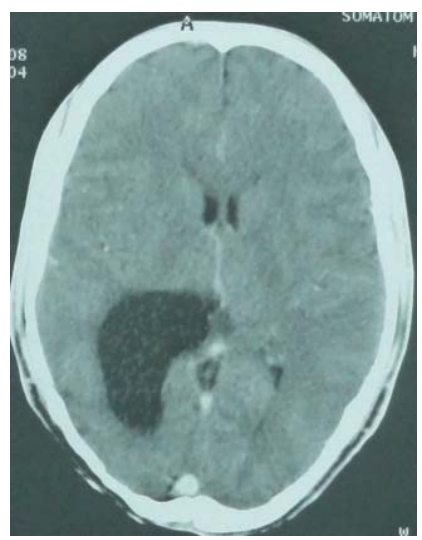

(c)

Figure 2. CT scan controls in a week (a), at 3 months (b) and 12 months (c) after surgery showed a total disappearance of the lesion, leaving behind a hypodense lesion as a sequella.

and hydrocephalus $[3,8,10]$. MR imaging usually shows tuberculoma as peripherally isointense and centrally hypointense on T1-weighted images. The isointense region becomes hypointense on T2-weighted images with enhancement by gadolinium injection [4,10-12]. These data were found in our case. Now in our knowledge, the presence of high peripheral edema with asymmetric hydrocephalus might suggest the diagnosis of inflammatory pathology especially intraventriculartuberculoma. It's also said that traction of the septumpellucidum to the side of the lesion confirms the presence of an inflammatory process and is a diagnostic radiological sign [10]. But considering its rarity, some differentials diagnosis such plexus choroid tumor, intraventricularglioma or metastasis had been suggested before operation. Regarding this location and the limited capacity of our patient, we opted of a direct surgical approach that permitted to establish the histological diagnosis of tuberculoma and cure the hydrocephalus. But with the moderns imaging procedures (MRI with spectroscopy) and themoderns laboratory analyses (Gene amplification by the polymerase Chain reaction), it's possible to approach the diagnosis of tuberculoma and confirm it with a very little minimal approach such endoscopic technics in this location. This technic was performed by J. P. Singh et al. [1].

However, some authors supported that if a diagnosis of tuberculoma is considered, a trial of antituberculoustherapy should be instituted even without histological confirmation [1]. That attitude can be discussed because, the tuberculosis disease required multidrug administration for a long course with several sides effects. It might be suitable to have a histological specimen before treatment.

Several authors recommendto use 3 or 4 majors antituberculous drugs in the first 2 months following by 10 months of 2 antituberculous drugs [11]. The use of steroids is controversial, but must be considered in some cases like ours with monstrous edema. The duration of treatment is uncertain, although treatment for more than 1 year is advocated by more clinicians $[10,11]$.

\section{CONCLUSION}

Intraventricular tuberculomais extremely rare. Regarding the mimickingappareance of intracranial tuberculomas and the long duration of the treatment, we strongly suggest to havehistological confirmation beforeantituberculous drug administration.

\section{ACKNOWLEDGEMENTS}

We would like to thank Mrs Barry Najah for her supports for this manuscript.

\section{REFERENCES}

[1] Singh, D.K. et al., (2011) Atypical presentation of intraventricul tuberculoma. Turkish Neurosurgery, 21, 242245.

[2] Bhargava, S., Gupta, A.K. and Tandon, P.N. (1982) Tuberculous meningitis: A CT study. British Journal of Radiology, 55, 189-196. doi:10.1259/0007-1285-55-651-189

[3] Hsu, P.W., Lin, T.K. and Chang, C.N. (2004) Solitaryintraventricular tuberculoma in adults. Acta Neurochirurgica, 146, 1151-1153. doi:10.1007/s00701-004-0291-7

[4] Ramamurthi, B. and Varadarajan, M.G. (1961) Diagnosis of tuberculomas of the brain: Clinical and radiological correlation. Journal of Neurosurgery, 18, 1. doi:10.3171/jns.1961.18.1.0001

[5] World Health Organization (2012) WHO global tuberculosis report.

http://www.who.int/tb/publications/global_report/en/inde x.html

[6] Berthier, M., Sierra, J. and Leiguarda, R. (1987) Intraventriculartuberculoma : Report of four cases in children. Neuroradiology, 29, 163-167. doi:10.1007/BF00327542 
[7] Desgeorges, M., Tranier, J., Mercier, P., Masselot, A. and Gendron, Y. (1977) Intraventricular cerebral tuberculoma: A propos of a case. Annals of Internal Medicine (Paris), 128, 541-544.

[8] Vajramani, G., Devi, B.I., Hegde, T., Santosh, V., Khanna, N. and Vasudev, M.K. (1999) Intraventricular tuberculous abscess: A case report. Neurology India, 47, 327-329.

[9] Desai, K., Nadkarni, T., Bhatjiwale, M. and Goel, A. (2002) Intraventricular tuberculoma. Neurologia MedicoChirurgica (Tokyo), 42, 501-503.

doi:10.2176/nmc.42.501

[10] Kendall, B., Grosswasser, I.R. and Valentine, A. (1983)
Diagnosis of masses presenting within the ventricules on computed tomography. Neuroradiology, 25, 11-22. doi:10.1007/BF00327474

[11] Singh, J.P. and Chandy, M.J. (1988) Third ventricular tuberculoma: A case report. British Journal of Neurosurgery, 2, 93-96. doi:10.3109/02688698808999664

[12] Sonmez, G., Ozturk, E., Mutlu, H., Sildiroglu, O., Haholu, A., Kutlu, A., Basekim, C. and Kizilkaya, E. (2007) An unusual intraventricular lesion: Tuberculoma. Journal of Neuroradiology, 35, 63-64.

doi:10.1016/j.neurad.2007.06.008 